\title{
Expression of Recombinant Fusion Protein of Newcastle Disease Virus from Escherichia coli Plasmid Clone C-2a by In-vitro Cell-free Protein Expression System
}

\author{
Ahmad Pandu Satria Wiratama ${ }^{1}$ and Aris Haryanto ${ }^{1 *}$ \\ ${ }^{1}$ Department of Biochemistry and Molecular Biology, Faculty of Veterinary Medicine, \\ Universitas Gadjah Mada, Jl.Fauna 2 Karangmalang, Yogyakarta 55281, Indonesia.
}

\begin{abstract}
Newcastle Disease Virus (NDV) is an infectious disease that infect many kinds of wild and domesticated birds. Infection of NDV become a massive problem for poultry industry around the world especially in Indonesia. Vaccination is an effort to prevent the infection of NDV in poultry. NDV vaccine that used in Indonesia is a conventional life vaccine from LaSota and B1 strains. These type of vaccine is $21 \%-23 \%$ genetically distinct with the virus that spread in the environment. The antibody protection provided by the vaccine is not effective. Therefore, vaccination with new local NDV strain is needed to prevent the NDV infection in Indonesia. The previously study research reported that the local isolate of NDV from Kulon Progo, Indonesia has been isolated. Fusion (F) protein encoding gene that has been inserted into pBT7-N-His expression plasmid which isolated from clone C-2a of E. coli, then it was expressed by the Cellfree protein expression system. The aim of this study was to confirm whether clone $\mathrm{C}-2 a$ of E.coli carrying a recombinant plasmid $\mathrm{pBT} 7-\mathrm{N}-\mathrm{His}-\mathrm{Fusion} \mathrm{NDV}$ and to express a recombinant F protein of NDV in-vitro from expression plasmid by cell-free protein expression system. This work started by detection of recombinant plasmid pBT7-N-His-Fusion NDV by DNA plasmid extraction followed by agarose gel electrophoresis. The recombinant $\mathrm{F}$ protein was in-vitro expressed by cell-free protein expression kit. The expressed F protein of NDV then was visualized by SDS-PAGE and Westernblott to analyse the expression of NDV recombinant F protein. It confirmed that clone $\mathrm{C}-2 \mathrm{a}$ of $E$. coli contained plasmid pBT7-N-His (4.001 bp) inserted by recombinant $\mathrm{F}$ protein of NDV gene $(642 \mathrm{bp})$. The visualisation of expressed recombinant $F$ protein by SDS-PAGE and Westernblott showed the NDV recombinant F protein was a specific protein fragment with molecular weight of 25,6 kDa..
\end{abstract}

\section{Introduction}

Newcastle Disease is an infectious disease that infects many kinds of poultry and become a huge problem for the poultry industry around the world. The outbreak of the disease can cause a high rate of mortality (up to $100 \%$ ), which are very detrimental to the poultry farmers [1].

Newcastle Disease is caused by NDV, which belongs to genus Avulavirus, family Paramyxoviridae and ordo mononegavirales. The genome of NDV is consist of negative single-strand RNA. The viral particle of NDV is enveloped with the surface of viral particle covered by spike glycoproteins, namely HaemagglutininNeuraminidase (HN) protein and Fusion (F) protein [2]. Based on the virulence and clinical symptoms in infected birds, NDV can be classified into five pathotypes, namely: viscerotropic velogenic which is a highly pathogenic NDV that is indicated by the haemorrhagic lesions in the intestinal mucosa with highly mortality rate. Velogenic neurotropic which is characterized by respiratory and nerve system disorders such as incoordination and torticollis which is characterized by high mortality rate. Furthermore, the moderate pathotype, which is mesogenic, is characterized by respiratory and nervous system disorders with a low mortality rate. Then NDV with a mild pathotype, namely lentogenic which is characterized by mild respiratory system disorders. The last is an asymptomatic enteric which is a subclinical enteric infection [1]

NDV infection process is depend on two major proteins, namely $\mathrm{HN}$ protein and $\mathrm{F}$ protein. The $\mathrm{HN}$ protein involved in virus particle attachment to the sialic acid receptor on the surface of host-cells. The F protein act to initiate the fusion of the viral envelopes and the host cell membranes [3,4]. On the surface of the virus particles, this protein is in the form of precursor Fo and can be activated if it split into F1 and F2 at the cleavage site. The amino acid sequence in the cleavage site is the main determinant of the viral virulence. In low virulenceNDV has cleavage site that can only be split by enzymes that found only in the cell of digestive and respiratory tract. Meanwhile, in high virulence-NDV, the cleavage site can be split by enzymes that found in all of host's cell [5].

Newcastle Disease can be prevented by vaccination. Newcastle Disease vaccine that easily found in Indonesia is conventional life vaccine from strain LaSota and strain B1. The vaccine from strain LaSota and B1 that available now are $21-23 \%$ genetically distinct from the virus that spread in the environment. This genetic difference causing ineffective protection against Newcastle Disease for poultry industry. So that new vaccine is need to be developed, especially vaccine for NDV that widely spread in environment in Indonesia [6].

Recombinant DNA technology allows us to produce large amounts of certain protein and can be purified to

* Corresponding author: arisharyanto@ugm.ac.id 
become a vaccine. The gene which is encode immunogenic virus protein can be inserted into a plasmid and expressed by certain bacteria [7]. Protein expression using AccuRapid ${ }^{\mathrm{TM}}$ Protein Expression Kit allows us to produce protein faster than conventional method because it doesn't require time to wait the bacteria growing and protein synthesize [8]. The objective of this study was to confirm whether clone C-2a E.coli carrying a recombinant plasmid $\mathrm{pBT} 7-\mathrm{N}-\mathrm{His}-\mathrm{Fusion} \mathrm{NDV}$ and to express a recombinant $\mathrm{F}$ protein of NDV in vitro from expression plasmid by cell-free protein expression system.

\section{Materials and Methods}

The sample used for this study was the recombinant plasmid of pBT7-N-His produced by Bioneer Corporation, South Korea which has been modified by Wulanjati et al., [9]. The plasmid was isolated from $E$. coli strain BL-21 colony named clone C-2a. The plasmid was already inserted with gene encoding $\mathrm{F}$ protein of local NDV which isolated from Kulon Progo, Yogyakarta, Indonesia.

\subsection{Samples preparation}

To find out whether the sample used contained pBT7-NHis plasmid, which had been inserted by recombinant $F$ protein encoding gene of NDV, the sample was electrophoresed in 1\% agarose gel. Fluorosafe DNA Stain was added and then poured into a gel mold until solidified. The first well was loaded with a marker of 100 bp of DNA ladder in volume of $6 \mu \mathrm{L}$. The second well was loaded with the mixture of $1 \mu \mathrm{L}$ sample, $2 \mu \mathrm{L}$ of loading dye, and $3 \mu \mathrm{L}$ of aquadest. After that, the gel was inserted into an electrophoresis tank containing 1x TBE solution. Then the running process was carried out with 80 volt electricity for 45 minutes. Then the electrophoresis results can be analysed by looking under a UV transilluminator.

\subsection{Digesting recombinant plasmid with Eco R1}

The plasmid sample was then digested by Eco RI. This process was carried out in a total mixture of $10 \mu \mathrm{l}$, containing plasmid of $2 \mu \mathrm{L}$. Eco $R I$ enzyme of $1 \mu \mathrm{L}$, enzyme buffer of $1 \mu \mathrm{L}$, and aquadest of $6 \mu \mathrm{L}$. The mixture was then incubated in $37^{\circ} \mathrm{C}$ for 3 hours. To find out whether the plasmid was digested by the restriction enzyme, they were then all samples were separated by electrophoresis, as previously explained.

\subsection{In-vitro Protein Expression}

In-vitro expression of $\mathrm{F}$ protein from the gene which already inserted to pBT7-N-His plasmid from clone C-2a of $E$. coli using AccuRapid ${ }^{\mathrm{TM}}$ Cell-free Protein Expression Kit (Bioneer Corp., South Korea). In a set of the expression kit is containing Master mix, E. coli extract, DNA template for positive control, and DEPC water. The process started by preparing three eppendorf tubes, a tube for negative control, positive control, and sample. All of components were then loaded into each tube with composition listed in Table 1 . Then all of the tubes were incubated in temperature of $30^{\circ} \mathrm{C}$ for 45 minutes.

Table 1. Composition of AccuRapid ${ }^{\mathrm{TM}}$ protein expression system.

\begin{tabular}{lccc}
\hline \multicolumn{1}{c}{ Component } & $\begin{array}{c}\text { Negative } \\
\text { Control }\end{array}$ & $\begin{array}{c}\text { Positive } \\
\text { Control }\end{array}$ & Sample \\
\hline Master mix $(\mu \mathrm{L})$ & 21 & 21 & 21 \\
E.coli extract $(\mu \mathrm{L})$ & 12 & 12 & 12 \\
DEPC water $(\mu \mathrm{L})$ & 12 & 11 & 8 \\
DNA template $(\mu \mathrm{L})$ & - & 1 & 4 \\
Total $(\mu \mathrm{L})$ & 45 & 45 & 45 \\
\hline
\end{tabular}

\subsection{Sodium Dodecyl Sulphate-Polyacrylamide Gel Electrophoresis}

The expressed protein then electrophoresed using Sodium Dodecyl Sulphate Polyacrylamide Gel Electrophoresis (SDS-PAGE). The polyacrylamide gel concentration on separating gel was $12 \%$. After homogeneous, poured it into the gel mold and added butanol at the top of gel, so that there was no air bubbles and flat gels. It was added by $5 \%$ stacking gel to the top of the gel. Stacking gel was made by mixing $5 \mathrm{ml}$ stacking gel 5\% with $5 \mathrm{ml}$ TEMED and $50 \mathrm{ml} \mathrm{APS} 10 \%$ and It was poured into the gel mold. Once the gel was compacted, the polyacrylamide gel was inserted into the electrophoresis tank and soaked in protein electrophoresis buffer of Tris- $\mathrm{HCl}$, glycine, and SDS $10 \%$.

The next step was sample preparation by moving of $5 \mu \mathrm{L}$ from each negative control, positive control, and the product of protein expression into the other three tubes. The $10 \mu \mathrm{L}$ of DEPC water and $5 \mu \mathrm{L}$ loading dye were added to each tube. Then all of the tubes were incubated for five minutes. Then load the negative control, positive control, and sample into the wells of the gel and electrophoresed for two hours in 100 volt.

After the running process was done, the next step was stained to colour the electrophoresed protein. The gel with electrophoresed protein was soaked in staining solution which contains Coomassie blue for 24 hours. It was moved to another container which filled with destaining solution which contains aquadest, methanol, and acetic acid three times for 40 minutes.

\subsection{Western Blot}

The last step of the method is Westernblot. This process begun with transferring the product of protein electrophoresis from gel to PVDF membrane which already soaked with methanol for one hour. Blotter which filled with transfer buffer is used for transfer process. The order of arrangement of western blot used from anode to the cathode was the three layers of thick Whatman paper, three layer of thin Whatman paper, PVDF membrane, 
SDS-PAGE gel, followed by three layer of thin Whatman paper, three layer of thick Whatman paper. Westernblot tools are closed then by blotting process started for an hour in $500 \mathrm{~mA}$ of current.

The next step is blocking, the PVDF membrane was soaked into blocking solution (BSA, TBS buffer $\mathrm{pH}$ 7.5, and Tween) for 10 minutes. The $6 \mathrm{x}$ mouse epitope tag antibody (Invitrogen, Canada) added as much as $5 \mathrm{ml}$ as a primary antibody and then diluted a comparison of 1:2000 with 5\% BSA and $0.1 \%$ TBS Tween and was incubated one night in a temperature of $4 \mathrm{oC}$. After the incubation process, the PVDF membrane is washed with $0.05 \%$ TBS Tween 2 times each 5 minutes and 1 time 10 minutes. Washing results added conjugate goat antimouse IgG Affinity Purify (comparison 1:15,000 as secondary antibody with $1 \%$ BSA in $0.05 \%$ TBS Tween then incubated for 1 hour in room temperature using shaker. After the incubation process completed, the PVDF membrane is washed with TBS Tween $0.05 \% 2$ times each 5 minutes and 2 times each 10 minutes. The result of washing is added substrate 1-StepTM NBT/BCIP until visible ribbon with specific position depending on protein size. The results of these ribbons show the weight of each specific protein.

\section{Result and Discussion}

Before in-vitro protein expression, sample of DNA plasmid which isolated from $E$. coli clone C-2a need to be electrophoresed to confirm whether the $E$. coli clone C-2a contains plasmid pBT7-N-His which already inserted with recombinant $\mathrm{F}$ protein encoding gene or not. The result of electrophoresis was shown in figure 1 .

The recombinant plasmid of pBT7-N-His-Fusion NDV that already inserted with recombinant $F$ protein encoding gene was $4.643 \mathrm{bp}$ in total length. From the result of electrophoresis, there was a thick DNA band slightly above the marker of $3.000 \mathrm{bp}$, we assumed the DNA band was the real recombinant plasmid of pBT7-NHis-Fusion NDV which already successfully inserted with recombinant $\mathrm{F}$ protein encoding gene. This result confirmed that the sample isolated from colony of $E$. coli clone C-2a contained pBT7-N-His plasmid which inserted with $\mathrm{F}$ protein encoding gene of local NDV. Figure 1 showed that electrophoresis of recombinant plasmid PBT7-N-His-Fusion NDV, there was three DNA bands, namely circularly conformation plasmid as top DNA band, linear conformation plasmid as the middle DNA band and the supercoil conformation plasmid ass the bottom DNA [10].

To confirm the gene that inserted in pBT7-N-HisFusion NDV plasmid was F protein encoding gene, the plasmid was digested with Eco RI restriction enzyme, since the cloning site of plasmid pBT7-N-His-Fusion $\mathrm{NDV}$ where the $\mathrm{F}$ protein encoding gene was inserted between two restriction sites of Eco RI enzyme. After the digestion was performed, the restriction product was electrophoresed, the result of the electrophoresis shown in Figure 2.

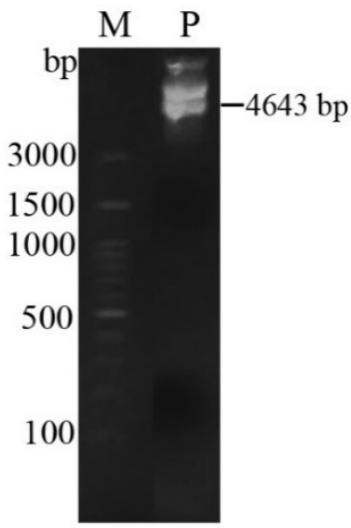

Figure 1. Electrophores is result of the sample isolated from clone C-2a of $E$. coli. $\mathrm{M}=$ Marker DNA ladder 100 $\mathrm{bp}, \mathrm{P}=$ plasmid isolated from clone $\mathrm{C}-2 \mathrm{a}$ of $E$. coli.

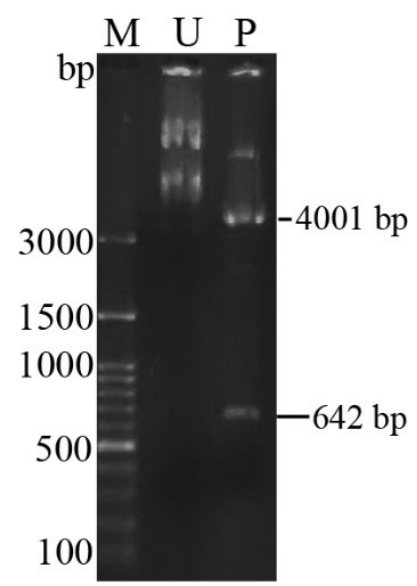

Figure 2. Electrophoresis result of the Eco RI digestion product on plasmid pBT7-N-His isolated from C-2a clone. $\mathrm{M}=$ Marked DNA ladder $100 \mathrm{bp}, \mathrm{U}=$ undigested pBT7-N-His plasmid, $\mathrm{P}=$ Eco RI digested pBT7-N-His.

In the $U$ lane, there was three bands of DNA plasmid. Those bands are undigested pBT7-N-His plasmid with $4.643 \mathrm{bp}$ in length, but since the plasmid has three conformation, it form three bands instead of one band. The top band was plasmid with circularly conformation, the middle band was plasmid with linear conformation, and the bottom band was plasmid with supercoiled conformation [10].

In the P lane, three DNA bands are showed. The top band was $4.001 \mathrm{bp}$ in length pBT7-N-His-Fusion NDV plasmid without $\mathrm{F}$ protein gene insertion (the $\mathrm{F}$ protein gene was already removed by Eco RI), and the bottom band was F protein gene with $642 \mathrm{bp}$ length [11]. This electrophoresis result confirmed that pBT7-N-His plasmid which isolated from clone C-2a of $E$. coli was inserted with recombinant $\mathrm{F}$ protein gene of NDV, so the expression of $\mathrm{F}$ protein by AccuRapid ${ }^{\mathrm{TM}}$ Cell-free protein expression system can be carried out. In this method, the protein expression can be done with less time than conventional method, since in this method did not 
required plasmid transformation process into the bacteria and culture it [8].

The protein expression product can be visualized using $12 \%$ SDS-PAGE. The result of the SDS-PAGE shown in the Figure 3.

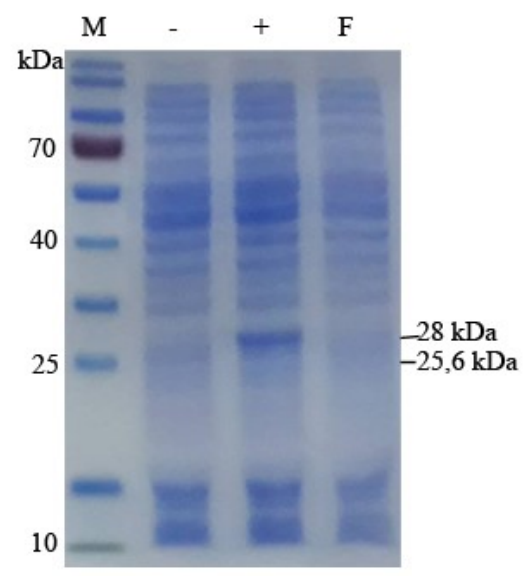

Figure 3. The result of SDS-PAGE on expression product from plasmid $\mathrm{pBT} 7-\mathrm{N}-\mathrm{His}$. $\mathrm{M}=$ Marker protein ladder, $(-)=$ negative control, $(+)=$ positive control, $\mathrm{F}=$ the expression product.

From the SDS-PAGE, in the (-) column, there are some bands of proteins. Those bands are formed by the proteins from E.coli extract and master mix from the expression kit. In the $(+)$ column, there was a protein band with $28 \mathrm{kDa}$ of molecular weight that distinct from the bands formed by the proteins from the expression kit. This band was formed by Aequore coerulescens GFP Fluorescent Protein (AcGFP) that expressed by the template for positive control [12]. In the F column, there was a band of protein with $25,6 \mathrm{kDa}$ of molecular weight which formed by the recombinant F protein of NDV that expressed from the gene that inserted into pBT7-N-HisFusion NDV plasmid.

In the SDS-PAGE result, the bands formed by various kinds of protein are still visualized. So that more specific visualization was needed. Each protein that expressed in positive control and in the expression product of recombinant $F$ protein was already attached by $6 \mathrm{x}$ his-tag. The presences of these $6 \mathrm{x}$ his-tag can be utilized to carry out the Westernblot technique. Principle of Westernblot technique was detecting the presence of 6x his-tag in the proteins that already transferred into PVDF membrane from electrophoresis gel using primary antibody that specifically attached to the $6 \mathrm{x}$ his -tag. Then the secondary antibody which conjugated with certain enzyme was added to detect the primary antibody that already attached to the $6 \mathrm{x}$ his-tag in each protein. The enzyme substrate in the secondary antibody was added to visualize the protein which expressed. The result of the Westernblot process is shown in figure 4.

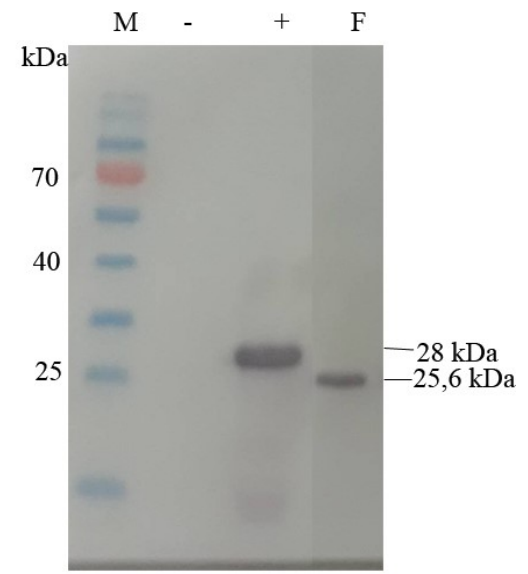

Figure 4. The result of Westernblot on expression product from plasmid $\mathrm{pBT} 7-\mathrm{N}-\mathrm{His}$. $\mathrm{M}=$ Marker protein ladder, $(-)=$ negative control, $(+)=$ positive control, $\mathrm{F}=$ the expression product

Westernblot result showed in the negative control column, there was no band showed since there are no protein attached with $6 \mathrm{x}$ his-tag was expressed in negative control. In the positive control there was a protein band with $28 \mathrm{kDa}$ molecular weight which formed by AcGFP protein that attached by 6x his -tag. In the $\mathrm{F}$ column, there was a protein band with $25,6 \mathrm{kDa}$ which formed by recombinant $F$ protein which attached by $6 \mathrm{x}$ his -tag that detected by Westernblot process. This expressed $\mathrm{F}$ protein of NDV from the clone C-2a E. coli were in line with the protein expression study conducted by researchers [13], who have successfully expressed the recombinant $\mathrm{F}$ protein of NDV from another $E$ coli clone, namely the clone $\mathrm{C}-1 \mathrm{a}$.

\section{Conclusion}

It concluded that $E$. coli clone $\mathrm{C}-2$ a contained plasmid pBT7-N-His (4.001 bp) inserted by recombinant $F$ protein of NDV gene (642 bp). The visualisation of expressed recombinant $F$ protein by SDS-PAGE and Westernblott showed the NDV recombinant $F$ protein was a specific protein fragment with molecular weight of $25,6 \mathrm{kDa}$.

\section{References}

1. Emilia, Setiyaningsih, and Soedjono. Jurnal Kedokteran Hewan. 9: 47-51, (2015)

2. B. Markey, F. Leonard, M. Archambault, A. Cullinane, and D. Maguire. Clinical Veterinary Microbiology. Second ed. 645-652, (2013)

3. A. Romer-Oberdorfer, O. Werner, J. Veits, T. Mebatsion, and T.C. Mettenleiter. J. Gen. Virol. 84: 3121-3129, (2003)

4. E. Ahmadi, S. Ali Pourbakhsh, M. Ahmadi, and A. Talebi. Turk. J. Vet. Anim. Sci. 38: 383-387, (2014)

5. O.S. Leeuw, L. Hartog, G. Koch, and B.P.H. Peeters.. J. Gen. Virol. 84:475-484, (2003) 
6. K. Shin-Hee, Z. Chen, A. Yoshida, A. Paldural, S. Xiao, and S.K. Samal. PLOS One, 12: 1-11, (2017)

7. F.A. Murphy, E.P.J. Gibbs, M.C. Horzinek, and M.J. Studdert. Veterinary Virology. Third ed. 245-259, (1999)

8. O. Kovtun, S. Mureev, W. Jung, M.H. Kubala, W. Johnston, and K. Alexandrov. Methods. 55: 58-64, (2011)

9. M.P. Wulanjati, N. Wijayanti, and A. Haryanto. Biotechnol. 17: 54-59, (2018)

10. S. Magdeldin. Gel Electrophoresis-Principles and Basics. In Tech. Rijeka. 49-51, (2012)

11. R.W. Astuti. Thesis. Magister Bioteknologi. Sekolah Pas casarjana, UGM. Yogyakarta, (2018)

12. Bioneer. AccuRapid ${ }^{\mathrm{TM}}$ Cell-Free protein expression kit.https://us.bioneer.com/products/Protein/Cell-Free ProteinExpressionKit-technical.aspx. accessed on February $5^{\text {th }}, 2020$, (2016)

13. C.N Putri and A. Haryanto. IOP Conference Series: Earth Environ. Sci. 355 (1). 012026, (2019) 